\title{
Comment on van Rongen et al., "Higher Midazolam Clearance in Obese Adolescents Compared with Morbidly Obese Adults"
}

\author{
David M. Reith ${ }^{1} \cdot$ Hesham Saleh Al-Sallami ${ }^{2}$ \\ Published online: 23 June 2018 \\ (c) Springer International Publishing AG, part of Springer Nature 2018
}

\section{Dear Editor,}

We have read with interest the recent study by van Rongen et al. comparing midazolam clearance in obese adolescents with morbidly obese adults [1]. The authors attributed a higher midazolam clearance in the obese adolescents group to higher cytochrome P450 3A enzyme activity when compared to the morbidly obese adults group. However, the surgery type in the obese adults appears to have been exclusively laparoscopic procedures, whereas the surgery in the obese adolescents appears to have been predominantly orthopaedic and otolaryngeal procedures [2,3]. Laparoscopy, with the associated pneumoperitoneum, has been shown to decrease portal venous blood flow by approximately half, with a paradoxical increase in hepatic artery blood flow by approximately $20 \%$, and apparent effects on drug clearance [4]. This effect could also account for the apparent differences in clearance between obese adolescents and morbidly obese adults in the van Rongen et al. study. Depending on the relative timing of the dosing and the onset of the pneumoperitoneum, the effect could also mimic structural pharmacokinetic model elements, such as an extra compartment, as described in Brill et al. [3]. Have the authors considered these effects in the development of the structural model and also the covariate modelling? Some patients in the obese adolescents group underwent bariatric surgery. If these procedures were laparoscopic, then it would be interesting to explore the influence of surgery type on

This comment refers to the article available at https://doi. org/10.1007/s40262-017-0579-4.

David M. Reith

david.reith@otago.ac.nz

1 Dunedin School of Medicine, University of Otago, Dunedin, New Zealand

2 School of Pharmacy, University of Otago, Dunedin, New Zealand drug clearance. It would also be interesting to model intraperitoneal pressure during laparoscopy, if these data are available, as a covariate effect.

Funding No funding was received for the preparation of this letter.

\section{Compliance with Ethical Standards}

Conflict of interest David M. Reith and Hesham Saleh Al-Sallami have no conflicts of interest directly relevant to the content of this letter.

\section{References}

1. van Rongen A, Brill MJE, Vaughns JD, Valitalo PAJ, van Dongen EPA, van Ramshorst B, et al. Higher midazolam clearance in obese adolescents compared with morbidly obese adults. Clin Pharmacokinet. 2018;57(5):601-11.

2. van Rongen A, Vaughns JD, Moorthy GS, Barrett JS, Knibbe CA, van den Anker JN. Population pharmacokinetics of midazolam and its metabolites in overweight and obese adolescents. Br J Clin Pharmacol. 2015;80(5):1185-96.

3. Brill MJ, van Rongen A, Houwink AP, Burggraaf J, van Ramshorst B, Wiezer RJ, et al. Midazolam pharmacokinetics in morbidly obese patients following semi-simultaneous oral and intravenous administration: a comparison with healthy volunteers. Clin Pharmacokinet. 2014;53(10):931-41.

4. Liu Y, Cao W, Liu Y, Wang Y, Lang R, Yue Y, et al. Changes in duration of action of rocuronium following decrease in hepatic blood flow during pneumoperitoneum for laparoscopic gynaecological surgery. BMC Anesthesiol. 2017;17(1):45. 